\title{
Editorial: Team and Leader Communication in the Healthcare Context: Building and Maintaining Optimal Transdisciplinary Teams
}

\author{
Leah M. Omilion-Hodges ${ }^{1 *}$, Rebecca Imes $^{2}$ and Jennifer Hester ${ }^{3}$ \\ ${ }^{1}$ School of Communication, Western Michigan University, Kalamazoo, MI, United States, ${ }^{2}$ Department of Communication and \\ Sociology, Carroll University, Waukesha, WI, United States, ${ }^{3}$ Christ Hospital, Cincinnati, OH, United States
}

Keywords: team and leader communication, transdisciplinary teams, healthcare, health communication, organizational obstacles, effective teams, patient-centered care, adept communication

\section{Editorial on the Research Topic}

Team and Leader Communication in the Healthcare Context: Building and Maintaining Optimal Transdisciplinary Teams

While the healthcare industry is moving away from the outmoded model of the individual provider as sole expert to the more contemporary, team-based approach, there remains a gap among theory, research, and practice. Before exploring the pressure points or the underlying reasons that challenges persist in effective team-based healthcare, we will discuss why teams are lauded as the gold standard for patient-centered care.

What does a team offer that an individual healthcare professional cannot? Teams bring sheer

Edited and reviewed by: Rukhsana Ahmed, University at Albany, United States

${ }^{*}$ Correspondence: Leah M. Omilion-Hodges leah.omilion-hodges@wmich.edu

Specialty section: This article was submitted to Health Communication, a section of the journal Frontiers in Communication

Received: 18 February 2021 Accepted: 18 May 2021 Published: 01 June 2021

Citation: Omilion-Hodges LM, Imes $R$ and Hester J (2021) Editorial: Team and

Leader Communication in the Healthcare Context: Building and Maintaining Optimal

Transdisciplinary Teams.

Front. Commun. 6:669399. doi: $10.3389 /$ fcomm.2021.669399 strength in terms of knowledge, know how, critical thinking and brainstorming ability. Additionally, patient care delivered via transdisciplinary teams often results in patients undergoing fewer tests, eradicating duplicative tests, improved efficiency, and improved patient outcomes including satisfaction (e.g., Lemieux-Charles and McGuire, 2006; Epstein, 2014). Since the research is clear that a team-based approach is the most effective way to care for patients and the healthcare industry is organized around patient care, why is a transdisciplinary approach not the standard?

Like any relationship, teams take energy, attention, and maintenance. Thus, merely arranging a group of individuals together and calling them a team, will be no more effective than uniting aroup of strangers and calling them a family. Teams need to be intentional to be effective and this means putting in effort above and beyond patient care. This translates to asking busy professionals, many of whom are already inundated and overloaded, to make time for additional meetings, perhaps some job shadowing, and to be available for more formal and informal conversations. We would be remiss if we did not also acknowledge that poorly constructed teams can also result in status and power hierarchies, increase providers' stress levels, and exacerbate provider burnout. Yet, research (e.g., Baker et al., 2006; Ledford et al., 2016) also finds a multitude of benefits for practitioners when teams function properly, including reduced stress, increased role satisfaction, and reduced turnover.

What are common characteristics effective teams share? They demonstrate planning, leadership, administrative support, and an unwavering commitment to communication. In the absence of a plan, when obstacles emerge or opinions conflict, without team guidelines and processes in place power struggles may emerge and providers are likely to retreat to their disciplinary silos. Not only does siloing defeat the purpose of a team-based approach, but it can also make providers weary of working with others.

Considering the shift toward the delivery of team-based care coupled with the challenges that are part and parcel with this work, this research topic offers a wealth of empirical findings and pragmatic 
solutions. While each article offers unique and meaningful contributions, they also share several striking similarities. Chief among them, each of the articles underscores the importance of communication, the complexity inherent in teams and team decision-making processes, and the high-stakes environment of healthcare. Yet, as each author points out conflict and argument can be healthy as they indicate that members are passionate and engaged. The presence of conflict also means that there are natural opportunities to learn from others and consider different points of view. This research topic of articles addresses some of the challenges of teamwork in the healthcare setting, while highlighting the wealth of positive outcomes.

Zajac et al. take a broad approach to teamwork in healthcare seeking to tie to gather literature from disparate research areas to offer a framework for team effectiveness and an accompanying diagnostic tool. The authors accomplish this work in part by identifying common challenges to teamwork in healthcare and in response, offer data-driven solutions. Zajac et al. did not stop at a substantive review of extant literature; the research team conducted a series of interviews with healthcare professionals and tested their diagnostic tool across 10 teams. The result? A framework that can be employed across medical specialties while also geared to helping teams continue to develop collectively.

Relatedly, Dinh et al. further what is known regarding teamwork in healthcare, but with a more specific focus on critical care domains: Surgery, trauma, emergency medicine, and resuscitation. The authors considered various teamwork practices such as operationalizing action, transition, and interpersonal processes. Perhaps not surprisingly, the researchers found that healthcare teams are likely to achieve greater levels of success by focusing on more collaborative and interpersonal approaches to teamwork, emphasizing the need for adept communication.

In a study that spans over 800 cancer cancers, Soukup et al. examined the prevalent role communication played in the context

\section{REFERENCES}

Baker, D. P., Day, R., and Salas, E. (2006). Teamwork as an Essential Component of High-Reliability Organizations. Health Serv. Res. 41 (4p2), 1576-1598. doi:10. 1111/j.1475-6773.2006.00566.x

Epstein, N. (2014). Multidisciplinary In-Hospital Teams Improve Patient Outcomes: A Review. Surg. Neurol. Int. 5 (Suppl. 7), 295-S303. doi:10.4103/ 2152-7806.139612

Ledford, C. J. W., Canzona, M. R., Cafferty, L. A., and Kalish, V. B. (2016). Negotiating the Equivocality of Palliative Care: a Grounded Theory of Team Communicative Processes in Inpatient Medicine. Health Commun. 31 (5), 536-543. doi:10.1080/10410236. 2014.974134 of multidisciplinary teams. Weekly tumor board meetings were filmed across through teaching hospitals in the United Kingdom and were reviewed to consider how communication functions along side time pressure, workload, task complexity, logistical issues, and group composition. In short, the authors bring us findings from among the most common and realistic of teambased work. Soukup et al. found that smaller sized, gender balanced teams with core disciplines present can serve to streamline workload concerns and reduce time-workload pressure as well. These factors can also contribute to more conducive team building and maintenance.

The research topic also features a case study that highlights challenges that can emerge in the care vs cure dialectic. While most providers would acknowledge that they strive to integrate their focus on care and cure, for certain cases it may feel like these two foci are instead competing and at odds. Spates et al.consider the important role that hospital chaplains play in meeting patient's needs and caring for the whole patient. This case study does an exemplary job of acknowledging and exploring the communication challenges of membership on transdisciplinary teams.

This research topic is dedicated to the scores of healthcare professionals and employees who work tirelessly day in and out to deliver patient-centered care; for those who work in teams now and those who may find themselves in teams in the future. It is our sincere hope that this research topic helps to ease some of the organizational stressors healthcare providers experience, so that you may focus on what is most important-your patients.

\section{AUTHOR CONTRIBUTIONS}

LO-H lead editorial efforts with $\mathrm{RI}$ and $\mathrm{JH}$ contributing substantially to the process.

Lemieux-Charles, L., and McGuire, W. L. (2006). What Do We Know about Health Care Team Effectiveness? A Review of the Literature. Med. Care Res. Rev. 63 (3), 263-300. doi:10.1177/1077558706287003

Conflict of Interest: The authors declare that the research was conducted in the absence of any commercial or financial relationships that could be construed as a potential conflict of interest.

Copyright (c) 2021 Omilion-Hodges, Imes and Hester. This is an open-access article distributed under the terms of the Creative Commons Attribution License (CC BY). The use, distribution or reproduction in other forums is permitted, provided the original author(s) and the copyright owner(s) are credited and that the original publication in this journal is cited, in accordance with accepted academic practice. No use, distribution or reproduction is permitted which does not comply with these terms. 